\title{
Antisymmetry in female strobili of Pinus taeda
}

\author{
Pie, MR.*, Tschá, MK. and Marteleto, FM. \\ Setor de Ciências Biológicas, Departamento de Zoologia, Centro Politécnico, \\ Universidade Federal do Paraná - UFPR, \\ CP 19073, CEP 81531-990, Jardim da Américas, Curitiba, PR, Brazil \\ *e-mail: pie@ufpr.br
}

Received January 30, 2007 - Accepted May 4, 2007 - Distributed November 30, 2007

(With 1 figure)

Spiral structures are a widespread theme in plant morphology, raising considerable interest amongst botanists and mathematicians for their relationship with Fibonacci numbers (see Cooke. 2006 for a recent review). Most of this research has focused on phyllotaxis, the study of the relative arrangement of repeated units, such as leaves around a stem, etc. (Jean, 1994; Adler et al. 1997). Several hypotheses have been provided to explain the pervasiveness of phyllotaxis in plant morphology, such as an increased light reception efficiency in the case of leaves (e.g. Valladares and Brites, 2004; Brites and Valladares 2005), but the understanding of the adaptiveness of phyllotaxis has been elusive.

A phenomenon closely related to (but conceptually independent from) phyllotaxis is antisymmetry, the presence of alternative orientations of the asymmetric structures (Palmer, 2005). The female strobili of pines, commonly known as pine cones, are an ideal model system to study antisymmetry in plants. These structures are composed of scales forming a series of spirals, also known as parastichies, which determine the orientation of the cone. The goal of the present study is two-fold. First, we assess whether there are statistically significant deviations from a 50:50 proportion of left- and right-spiraling pine cones. We also test whether there is a genetic predisposition for any given direction by comparing the orientation of cones from the same tree (and thus of the same genotype).

Collections were carried out in March 31, 2006 in the campus of the Universidade Federal do Paraná, in Curitiba, in Southern Brazil. A total of 500 cones of the slash pine Pinus taeda (Linnaeus) were collected and scored according to their orientation. In order to test if there is a genetic predisposition toward a given orientation, we collected an additional 20-50 pines from each of five trees (Figure 1).

A total of 244 clockwise and 256 counter-clockwise were collected and scored, indicating the lack of a statistically significant bias toward any given orientation $\left(\chi^{2}=0.28, p=0.59\right)$. Also, both orientations were equally as frequent in cones of the same trees (Table 1), indicating that, contrary to other asymmetries such as the apical-basal axis, which are strongly influenced by ma-
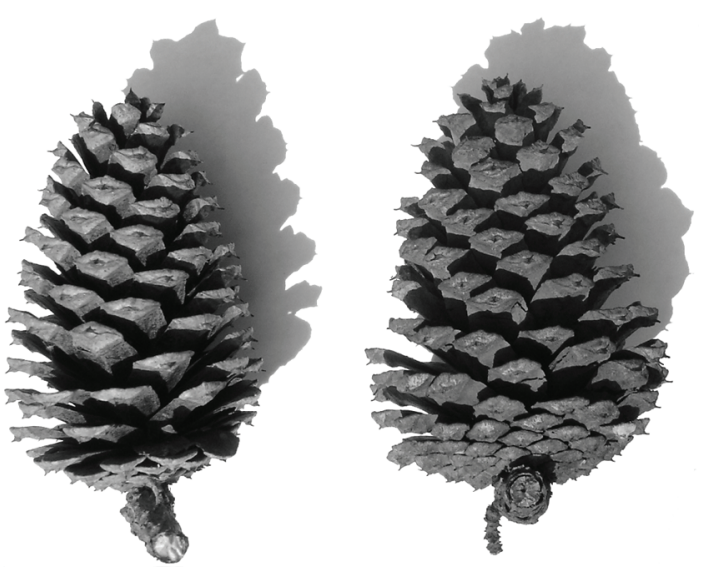

Figure 1. Pine cones indicating the clockwise (left) and counter-clockwise (right) orientations.

Table 1. Frequency distribution of pine cone orientation of Pinus taeda taken from individual trees. Spiral orientation terminology was based on Fredeen et al. (2002). Probabilities are based on the $\chi^{2}$ test.

\begin{tabular}{cccc}
\hline $\begin{array}{c}\text { Clockwise } \\
\text { spiral (\%) }\end{array}$ & $\begin{array}{c}\text { Counter-clockwise } \\
\text { spiral (\%) }\end{array}$ & $\mathbf{N}$ & $\mathbf{p}$ \\
\hline 54.5 & 45.5 & 22 & 0.76 \\
45.0 & 55.0 & 20 & 0.75 \\
27.3 & 72.7 & 22 & 0.12 \\
47.5 & 52.5 & 40 & 0.82 \\
44.2 & 55.8 & 52 & 0.55 \\
\hline
\end{tabular}

ternal effects and are determined even before fertilization (Hudson 2000), the orientation of the spiral in pine cones seems to be environmentally determined. Similar results have been recorded for Pinus contorta (Fredeen et al. 2002).

In conclusion, our results are consistent with the hypothesis that the direction of the spirals in pine cones are due to some symmetry-breaking mechanism at the early stages of meristem formation, and therefore are not genetically determined (Allard, 1945; Hudson, 2000). 
Acknowledgments - We thank D. B. Hungria for providing assistance with the illustration.

\section{References}

ADLER, I., BARABE, D., JEAN, RV. 1997. A history of phyllotaxis. Annals of Botany, vol. 80, no. 231-244.

ALLARD, HA. 1945. Clockwise and counterclockwise spirality in the phyllotaxy of tobacco. J. Agric., Res. vol. 71, no. 6 , p. 237-242.

BRITES, D. and VALLADARES, F. 2005. Implications of opposite phyllotaxis for light interception efficiency of Mediterranean woody plants. Trees, vol. 19, no. 6, p. 671-9.

COOKE, TJ. 2006. Do Fibonacci numbers reveal the involvement of geometrical imperatives or biological interactions in phyllotaxis? Botanical Journal of the Linnean Society, vol. 150, no. 1, p. $3-24$
FREDEEN, AL., HORNING, JA., MADILL, RW. 2002. Spiral phyllotaxis of needle fascicles on branches and scales on cones in Pinus contorta var. latifolia: are they influenced by woodgrain spiral? Can. J. Bot, vol. 80, no. 2, p. 166-175.

HUDSON, A. 2000. Development of symmetry in plants. Annu. Rev. Plant Physiol. Plant Mol. Biol. vol. 51, p. 349-370.

JEAN, RV. 1994. Phyllotaxis: a systemic study in plant morphogenesis. Cambridge and New York: Cambridge University Press.

PALMER, AR. 2005. Antisymmetry. In HALLGRIMMSON, B, and HALL, BK., Variation. Elsevier.

VALLADARES, F. and BRITES, D. 2004. Leaf phyllotaxis: does it really affect light capture? Plant Ecology, vol. 174, no. 1, p. 11-17. 